Short communication

\title{
Multiple biomarkers of biological effects induced by cadmium in clam Ruditapes philippinarum
}

\author{
Chenglong $\mathrm{Ji}^{\mathrm{a}}$, Huifeng $\mathrm{Wu}{ }^{\mathrm{a},{ }^{*}, \text { Mo Zhou }}{ }^{\mathrm{b}}$, Jianmin Zhao ${ }^{\mathrm{a}}$ \\ ${ }^{a}$ Key Laboratory of Coastal Zone Environmental Processes, Yantai Institute of Coastal Zone Research (YIC), Chinese Academy of Sciences (CAS), Shandong \\ Provincial Key Laboratory of Coastal Zone Environmental Processes, YICCAS, Yantai 264003, PR China \\ ${ }^{\mathrm{b}}$ Environment College, Northeast Normal University, Changchun 130024, PR China
}

\section{A R T I C L E I N F O}

\section{Article history:}

Received 2 February 2015

Received in revised form

14 March 2015

Accepted 15 March 2015

Available online 21 March 2015

\section{Keywords:}

Ruditapes philippinarum

Cadmium

Biological effects

Metabolomics

\begin{abstract}
A B S T R A C T
Cadmium (Cd) is a known heavy metal pollutant in the Bohai Sea. Manila clam Ruditapes philippinarum is an important fishery species along the Bohai coast. In this study, the biological effects induced by two concentrations ( 20 and $200 \mu \mathrm{g} / \mathrm{L}$ ) of $\mathrm{Cd}$ were characterized using multiple biochemical indices in the digestive glands of clam $R$. philippinarum. The total hemocyte counts, reactive oxygen species productions and antioxidant enzyme activities exhibited that $\mathrm{Cd}$ induced dose-dependent immune and oxidative stresses in clam digestive glands. Metabolic responses indicated that both $\mathrm{Cd}$ exposures caused immune stress marked by the elevated branched chain amino acids (valine, leucine and isoleucine), together with the disturbance in energy metabolism. The differential metabolic biomarkers related to osmotic stress, including homarine, betaine, tyrosine and phenylalanine, suggested the differential responsive mechanisms in clam digestive glands induced by $\mathrm{Cd}$ exposures. In addition, both $\mathrm{Cd}$ treatments enhanced the anaerobiosis metabolism in clam digestive glands via differential metabolic pathways.
\end{abstract}

(C) 2015 Elsevier Ltd. All rights reserved.

\section{Introduction}

Heavy metal pollution has become a serious environmental stressor to marine animals due to the adverse biological effects [1]. Among heavy metals, cadmium $(\mathrm{Cd})$ is a non-essential metal element for organisms and naturally found as an impurity with some minerals such as $\mathrm{Zn}$. In the Bohai marine environment, as reported, $\mathrm{Cd}$ has become one of the most serious metal pollutants because of the industrial discharge from numerous metal smelteries [2]. It is known that chronic accumulation of Cd may induce the itai-itai disease and carcinogenesis [3]. In addition, Cd can also induce oxidative stress by producing excessive reactive oxygen species in organisms [4].

Since Manila clam R. philippinarum is widely distributed along the Bohai coast and has a high tolerance to environmental changes (e.g., temperature, salinity), it has become one of the most important economic species in marine aquaculture in China. Furthermore, $R$. philippinarum is a preferred bioindicator in the "Mussel Watch Programs" for pollution biomonitoring. Therefore, this

\footnotetext{
* Corresponding author. Tel.: +86 535 2109190; fax: +86 5352109000.

E-mail address: hfwu@yic.ac.cn (H. Wu).
}

species is also often used as an experimental animal model on pollutant-induced biological effects [5-8].

Researchers often use a bottom-up approach to study responsive effects and mechanisms of pollutants, in which a few biochemical indices, such as the anti-oxidative enzyme activities, are tested for oxidative stress [9]. With the development of system biology, the omic techniques, including genomics, transcriptomics, proteomics and metabolomics, provide top-down approaches to explore the global profiles related to the biological perturbations induced by environmental stressors in organisms [10-13]. Researchers then can comprehensively profile one type of molecules such as genes, proteins and metabolites and their alterations to characterize the biological responses with high-throughput analyses. Among these omic techniques, metabolomics focuses on the whole set of low molecular weight $(<1000 \mathrm{Da})$ metabolites that are the end products in multiple biological systems including organs, tissues, biofluids, or even whole organisms [14,15]. Since metabolomics can directly characterize the perturbations in metabolic pathways, it may present an insightful view into the pollutantinduced effects in marine animals [16-20].

In this study, the biochemical responses induced by two sublethal concentrations ( 20 and $200 \mu \mathrm{g} / \mathrm{L}$ ) of Cd were studied by using both bottom-up and top-down approaches. In details, these 
biochemical indices, including the total hemocyte count (THC), production of reactive oxygen species, antioxidant enzyme activities and metabolic profile, were characterized to elucidate the biological effects of $\mathrm{Cd}$ in clam $R$. philippinarum after acute exposure for $48 \mathrm{~h}$.

\section{Materials and methods}

\subsection{Experimental animals and conditions}

Twenty four adult clams $R$. philippinarum (shell length: $3.5-3.8 \mathrm{~cm}, n=8$ from White pedigree) were purchased from local culturing farm in Yantai, China. After transported to the culture laboratory, the clams were allowed to acclimate in aerated seawater $\left(25^{\circ} \mathrm{C}, 33 \mathrm{psu}\right.$, collected from pristine environment) in the laboratory for 1 week and fed with the Chlorella vulgaris Beij at a ration of $2 \%$ tissue dry weight daily. After acclimation, the clams were randomly divided into three tanks (one control and two Cd exposures, respectively) containing eight individual clams in $20 \mathrm{~L}$ aerated seawater. Two sublethal concentrations (20 and $200 \mu \mathrm{g} / \mathrm{L}$ ) of $\mathrm{Cd}$ were selected for the exposures of $R$. philippinarum. After exposure for $48 \mathrm{~h}$, the hemolymph (approx. $350 \mu \mathrm{L}$ per sample) was sampled from the adductor muscle by a sterile syringe with the same volume of anticoagulant (50.0 mM Tris, $111.0 \mathrm{mM}$ Glucose, $341.9 \mathrm{mM} \mathrm{NaCl}, 25.5 \mathrm{mM}$ EDTA, pH 7.4). Samples were immediately filtered through a nylon mesh and kept individually in tubes held on ice to prevent hemocyte clumping until use. Then the digestive gland tissues of all the clams were dissected quickly and divided into three parts for metabolite extraction, assessment of antioxidant enzyme activities and determination of $\mathrm{Cd}$ accumulation. The samples of digestive gland tissues were flash-frozen in liquid nitrogen and stored at $-80{ }^{\circ} \mathrm{C}$ before further procedures.

\subsection{Total haemocyte count and reactive oxygen species}

The counting of free hemocytes was done by using a Neubauer hemocytometer according to a previous study with some minor modifications [21]. The hemocyte suspension fixed with $4 \%$ formalin was vortexed before transferring an aliquot of the suspension to a hemocytometer to quantify the total hemocytes under a light microscope (Olympus BX61, Tokyo, Japan). Three separate aliquots of the hemocyte suspension were counted and averaged for each clam. The data were presented as number of hemocytes/ $\mathrm{mL}$ hemolymph.

The production of reactive oxygen species (ROS) in hemolymph was assayed using $2^{\prime}, 7^{\prime}$-dichlorofluorescein diacetate (DCFH-DA, Sigma). Inside hemocytes, the -DA radicals is firstly hydrolyzed by esterase enzymes, and converted to $2^{\prime}, 7^{\prime}$-diclorofluorescein (DCFH), which emits fluorescence when reacting with ROS produced by the cell. Hemocyte suspensions diluted with PBS $(341.9 \mathrm{mM} \mathrm{NaCl}$,

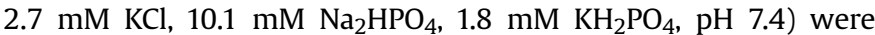
allowed to adhere for 20 min before adding DCFH-DA with the final concentration of $10 \mu \mathrm{M}$. After $60 \mathrm{~min}$ incubation at $18{ }^{\circ} \mathrm{C}$, DCF fluorescence intensity was measured using a flow cytometer (Becton-Dickinson, San Diego, CA, USA). The mean of fluorescence intensity of hemocyte population was expressed as arbitrary unit $(\mathrm{AU})$.

\subsection{Metabolite extraction}

Polar metabolites in clam digestive gland tissues $(n=8$ for each treatment) were extracted by the modified extraction protocol as described previously [19]. Briefly, the digestive gland tissue (ca. $100 \mathrm{mg}$ wet weight) was homogenized and extracted in $4 \mathrm{~mL} \mathrm{~g}^{-1}$ of methanol, $5.25 \mathrm{~mL} \mathrm{~g}^{-1}$ of water and $2 \mathrm{~mL} \mathrm{~g}^{-1}$ of chloroform. The methanol/water layer with polar metabolites was transferred to a glass vial and dried in a centrifugal concentrator. The extracts were then re-suspended in $600 \mu \mathrm{L}$ phosphate buffer $\left(100 \mathrm{mM} \mathrm{Na}_{2} \mathrm{HPO}_{4}\right.$ and $\mathrm{NaH}_{2} \mathrm{PO}_{4}$, including $0.5 \mathrm{mM}$ TSP, $\mathrm{pH} 7.0$ ) in $\mathrm{D}_{2} \mathrm{O}$. The mixture was vortexed and then centrifuged at $3000 \mathrm{~g}$ for $5 \mathrm{~min}$ at $4{ }^{\circ} \mathrm{C}$. The supernatant substance $(550 \mu \mathrm{L})$ was then pipetted into a $5 \mathrm{~mm}$ NMR tube prior to NMR analysis.

\section{4. ${ }^{1}$ H NMR spectroscopy}

Metabolite extracts of digestive gland tissues from clams were analyzed on a Bruker AV 500 NMR spectrometer performed at $500.18 \mathrm{MHz}$ (at $25^{\circ} \mathrm{C}$ ) as described previously [19]. All ${ }^{1} \mathrm{H}$ NMR spectra were phased, baseline-corrected, and calibrated (TSP at $0.0 \mathrm{ppm}$ ) manually using TopSpin (version 2.1, Bruker).

\subsection{Spectral pre-processing and multivariate analysis}

All one dimensional ${ }^{1} \mathrm{H}$ NMR spectra were converted to a data matrix using the custom-written ProMetab software in Matlab version 7.0 (The MathsWorks, Natick, MA) [19]. Each spectrum was segmented into bins with a width of $0.005 \mathrm{ppm}$ between 0.2 and $10.0 \mathrm{ppm}$. The bins of residual water peak between 4.70 and $5.20 \mathrm{ppm}$ were excluded from all the NMR spectra. The total spectral area of the remaining bins was normalized to unity to facilitate the comparison between the spectra. All the NMR spectra were generalized log transformed (glog) with a transformation parameter $\lambda=1.0 \times 10^{-8}$ to stabilize the variance across the spectral bins and to increase the weightings of the less intense peaks [19]. As described in details in our previous work, data were mean-centered before principal components analysis (PCA) using PLS Toolbox (version 4.0, Eigenvector Research, Manson, WA) [19]. Furthermore, the supervised multivariate data analysis methods, partial least squares discriminant analysis (PLS-DA) and orthogonal projection to latent structure with discriminant analysis (O-PLSDA), were sequentially carried out to uncover and extract the statistically significant metabolite variations related to Cd exposures, as described previously [22]. Metabolites were assigned following the tabulated chemical shifts and by using the software, Chenomx (Evaluation Version, Chenomx Inc., Edmonton, Alberta, Canada) [23].

\subsection{Antioxidant enzyme activities}

The antioxidant enzyme activities in the digestive gland tissues ( $n=8$ ) of $R$. philippinarum were assayed using a multimode microplate reader (Infinite M200, TECAN, Switzerland) according to the manufacturer's protocols for enzyme kits (Jiancheng, Nanjing, China). In this work, the antioxidant enzymes for the activity measurement included superoxide dismutase (SOD, EC 1.15.1.1), glutathione S-transferases (GST, EC 2.5.1.18) and glutathione peroxidase (GPX, EC 1.11.1.9). Protein concentration was determined by the Coomassie brilliant blue G-250 dye-binding method with bovine serum albumin as standard [24]. The unit of each enzyme was defined as the activity of an enzyme per milligram of total protein (U/mg protein).

\subsection{Determination of $\mathrm{Cd}$ in clam digestive gland tissues}

The digestive gland tissue samples $(n=5)$ of $R$. philippinarum were dried at $80{ }^{\circ} \mathrm{C}$ to constant weights. The dried tissues were digested in concentrated nitric acid (70\%, Fisher Scientific) using a microwave digestion system (CEM, MAR5). The samples were heated in the microwave oven (heating to $200{ }^{\circ} \mathrm{C}$ and holding at $200{ }^{\circ} \mathrm{C}$ for $15 \mathrm{~min}$ ). All completely digested samples were diluted 
with ultrapure water for the determination of Cd using ICP-MS technique (Agilent 7500i, Agilent Technologies Co. Ltd, Santa Clara, CA, USA). GBW08571 Marine mussel tissue was employed as a certified reference material for metal analysis to ensure internal quality assurance/quality control (QA/QC) practices [25]. The recovery of target elements, as tested by three individual spiking experiments, was restricted within $95.5 \%-104.3 \%$ for $\mathrm{Cd}$.

\subsection{Statistical analysis}

The biochemical indices, including THC, ROS, enzyme activities and $\mathrm{Cd}$ concentrations in clam digestive gland tissues, were expressed as means \pm standard deviation and tested for normal distribution (Ryan-Joiner's test) and homogeneity of variances (Bartlett's test). One way analysis of variance (ANOVA) with Tukey's test was conducted on these biochemical indices from control and Cd-exposed groups, respectively. A $p$ value less than 0.05 was considered statistically significant. The Minitab software (Version 15, Minitab Inc., USA) was used for the statistical analysis.

\section{Results and discussion}

Marine bivalves are known bio-accumulators of heavy metals due to their abundant metallothioneins and metallothionein-like proteins that have high capacities to bind metal ions in the organs, such as digestive glands and gills [26]. As shown in Table 1, the $\mathrm{Cd}$ concentrations in clam digestive gland tissues from both $\mathrm{Cd}-$ exposed groups (20 and $200 \mu \mathrm{g} / \mathrm{L}$ ) were significantly higher $(p<0.05)$ than that in control group. The significantly dosedependent accumulations of $\mathrm{Cd}$ in clam digestive glands implied that $\mathrm{Cd}$ exposure might induce detectable biological effects in clams.

For the low dose $(20 \mu \mathrm{g} / \mathrm{L})$ of Cd-treated clam samples, THC in haemolymph was not altered significantly compared with that in control group (Table 1). However, the average THC in the high dose $(200 \mu \mathrm{g} / \mathrm{L})$ of $\mathrm{Cd}$-treated clam samples were lower than that in control group with a $p$ value $(0.083)$ approaching 0.05 . Marine mollusks have an open circulatory system with hemocytes distributed in both vascular system and tissues. It is suggested that increased THC values may be caused by either proliferation or movement of cells from tissues into haemolymph, whereas decreased THC can be reflected by cell lysis or increased movement of cells from haemolymph to tissues [27]. Reid et al. reported that high THC values might enable $R$. philippinarum to improve the resistance to infection (Vibrio tapetis) [28]. In the present study, the reduced THC implied the decreased immunocompetence induced by the high dose $(200 \mu \mathrm{g} / \mathrm{L})$ of $\mathrm{Cd}$ in clam $R$. philippinarum. In addition, excessive ROS can cause oxidative stress which induces cell apoptosis. A significant increase $(p<0.05)$ of ROS production was observed in the high dose $(200 \mu \mathrm{g} / \mathrm{L})$ of Cd-treated clam group, which was negatively correlated with the THC values. This might suggest that the high dose $(200 \mu \mathrm{g} / \mathrm{L})$ of Cd induced oxidative stress leading to the decrease of THC and immunocompetence.
Antioxidant enzyme system is the basic defense system to resist the oxidative stress by scavenging of reactive oxygen species induced by environmental stressors [29]. Superoxide dismutases (SODs, EC 1.15.1.1) are metalloenzymes that play important roles in defenses against ROS and in particular superoxide anion by catalyzing the dismutation of superoxide into molecular oxygen and hydrogen peroxide [29]. In both Cd treatments, SOD activities were elevated with $p$ values approaching 0.05 (0.072 and 0.092, respectively). As the average ROS productions were also elevated in both Cd-treated clam groups, the elevated SOD activities meant that $\mathrm{Cd}$ exposures induced excessive superoxide anions in clam digestive gland. Both GST and GPx are related to GSH cycles that promote the conversion of GSH to resist the oxidative stress caused by environmental stressors. However, only GST activities were significantly depleted in both Cd-treated clam groups (Table 1), which might be accounted for the down-regulation of GST synthesis caused by $\mathrm{Cd}$ exposures in clam digestive gland tissues. In our previous study, Cd exposures down-regulated the mRNA expressions of GSTs in clam digestive glands, which was consistent with the alteration of GST activities in this work [7].

Metabolomics is a powerful technique to characterize the biological effects of environmental stressors in organisms [22,23,30,31]. A total of 31 metabolites, including amino acids (valine, leucine, isoleucine, alanine, arginine, etc.), an intermediate in the Krebs cycle (succinate), organic ormolytes (hypotaurine, dimethylglycine, betaine, taurine and homarine), energy storage compounds (glucose, ATP and glycogen), in clam digestive glands were identified and labeled in Fig. 1. PCA was performed on the NMR spectral data from control, low $(20 \mu \mathrm{g} / \mathrm{L})$ and high $(200 \mu \mathrm{g} / \mathrm{L})$ doses of Cd-treated clam samples. Obviously, PCA resulted in significant $(p<0.01)$ separations between control and Cd-treated groups along PC1 axis (Fig. 2). In addition, the control and low $\mathrm{Cd}$ treatment were also separated along PC2 axis. It clearly demonstrated the significant metabolic differences between control and Cd-treated groups. However, no significant $(p>0.05)$ separation between the two Cd-treated groups was found, which indicated that these two $\mathrm{Cd}$ exposures induced similar biological effects in clam digestive glands.

Further O-PLS-DA was performed on the NMR spectral data from control and each Cd-treated clam samples (Fig. 3). From the loading plot (Fig. 3B), the low concentration $(20 \mu \mathrm{g} / \mathrm{L})$ of Cd induced significant $(p<0.05)$ increases in branched chain amino acids (BCAAs), alanine, arginine, glutamate, glutamine, succinate, dimethylglycine, lysine, glucose, glycogen and homarine and a decrease in betaine. In the high concentration $(200 \mu \mathrm{g} / \mathrm{L})$ of Cd-treated clam samples, BCAAs, alanine, arginine, glutamate, succinate, lysine, glucose and glycogen were similarly increased. However, some differentially altered metabolic responses were observed in the high concentration $(200 \mu \mathrm{g} / \mathrm{L})$ of Cd-treated clam samples. In particular, tyrosine and phenylalanine were elevated, whereas aspartate was depleted.

As it is known, marine mollusks can use high concentrations of amino acids to regulate their intracellular osmolarity with their

Table 1

Biochemical indices in clam R. philippinarum samples after Cd exposures for $48 \mathrm{~h}$

\begin{tabular}{|c|c|c|c|c|c|c|}
\hline \multirow[t]{2}{*}{ Cd exposures $(\mu \mathrm{g} / \mathrm{L})$} & \multirow[t]{2}{*}{ Cd accumulation $(\mu \mathrm{g} / \mathrm{g} \mathrm{dw})$} & \multirow[t]{2}{*}{ THC $\left(\times 10^{6}\right.$ hemocytes/mL hemolymph $)$} & \multirow[t]{2}{*}{$\operatorname{ROS}\left(\times 10^{4} \mathrm{AU}\right)$} & \multicolumn{3}{|c|}{ Antioxidant enzyme activity (U/mg protein) } \\
\hline & & & & SOD & GST & GPx \\
\hline Control & $0.07 \pm 0.01$ & $3.43 \pm 0.66$ & $3.99 \pm 1.29$ & $3.87 \pm 0.87$ & $54.72 \pm 4.08$ & $5.18 \pm 1.56$ \\
\hline 20 & $0.18 \pm 0.05^{*}$ & $3.50 \pm 0.72$ & $4.36 \pm 1.98$ & $5.43 \pm 1.65^{\#}$ & $38.34 \pm 4.57^{*}$ & $3.35 \pm 2.87$ \\
\hline 200 & $0.66 \pm 0.13^{*}$ & $2.85 \pm 0.30^{\#}$ & $5.52 \pm 1.63^{*}$ & $4.81 \pm 0.39^{\#}$ & $39.74 \pm 6.62^{*}$ & $4.54 \pm 3.06$ \\
\hline
\end{tabular}

Data were expressed as mean \pm SD. Significant differences among groups were tested for by one-way analysis of variance with Tukey's test.

${ }^{*} p<0.05$.

${ }^{\#} 0.05<p<0.1$. 


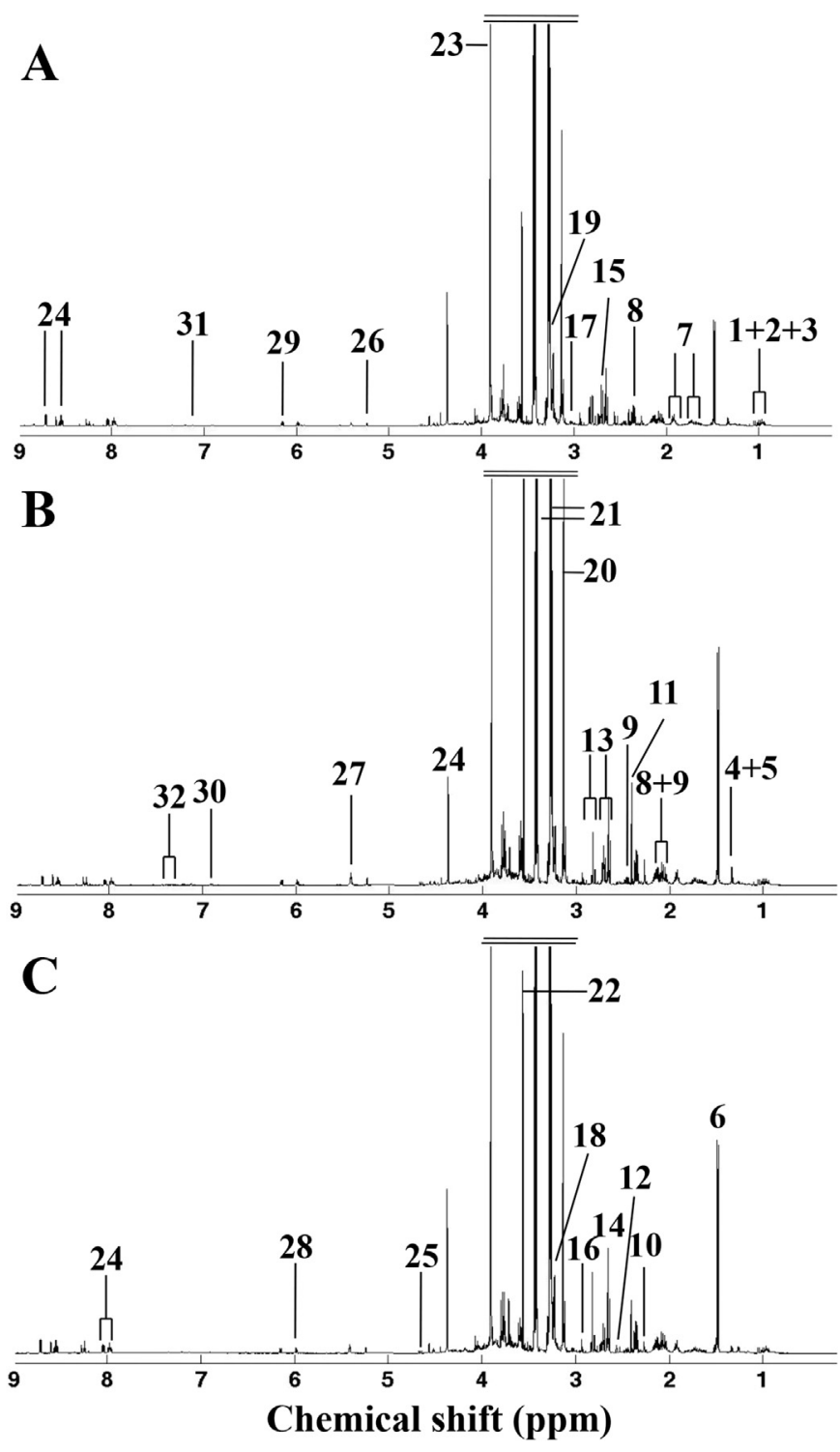

Fig. 1. Representative 1-dimensional $500 \mathrm{MHz}{ }^{1} \mathrm{H}$ NMR spectra of tissue extracts from digestive glands of $R$. philippinarum from (A) control, (B) low concentration (20 $\mu \mathrm{g} / \mathrm{L})$ and $(C)$ high concentration $(200 \mu \mathrm{g} / \mathrm{L})$ of Cd-exposed groups. Keys: (1) isoleucine, (2) leucine, (3) valine, (4) threonine, (5) lactate, (6) alanine, (7) arginine, (8) glutamate, (9) glutamine, (10) acetoacetate, (11) succinate, (12) $\beta$-alanine, (13) aspartate, (14) dimethylamine, (15) hypotaurine, (16) dimethylglycine, (17) lysine, (18) choline, (19) phosphocholine, (20) malonate, (21) taurine, (22) glycine, (23) betaine, (24) homarine, (25) $\beta$-glucose, (26) $\alpha$-glucose, (27) glycogen, (28) unknown 1 (5.98 ppm), (29) ATP, (30) tyrosine, (31) histidine and (32) phenylalanine.

environment [32]. The elevated amino acids indicated the osmotic stress induced by both Cd exposures ( 20 and $200 \mu \mathrm{g} / \mathrm{L}$ ) to clams. In another metabolic pathway, the BCAAs (valine, leucine and isoleucine) have availability on the immune system to function by incorporating BCAAs into proteins [33]. Upon pathogenic infection, there is a remarkable increase in demand for BCAAs for substrates by the immune system [33]. These BCAAs then provide energy and are used as the precursors for the biosynthesis of new protective molecules [33]. Therefore, the increased BCAAs might suggest the immune stress in clam immune organ, digestive gland, induced by both $\mathrm{Cd}$ exposures. In addition, the levels of two energy storage metabolites, glucose and glycogen, were significantly increased, which suggested the reduced energy demand in clams. Alanine constitutes the major portion of end-product of glucose breakdown

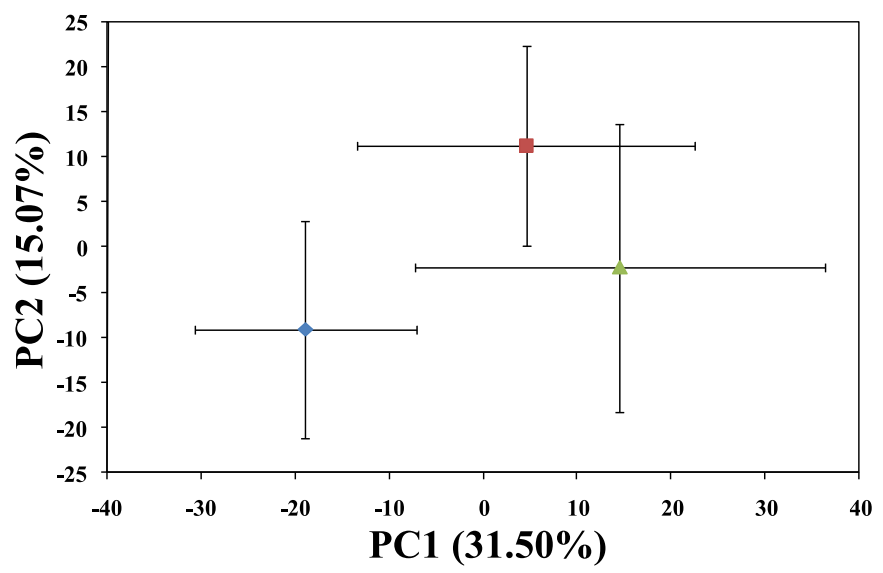

Fig. 2. Mean principal component analysis (PCA) scores plot of $P C 1$ versus $P C 2$ for ${ }^{1} \mathrm{H}$ NMR spectra of tissue extracts from digestive glands of $R$. philippinarum from control $(\diamond)$, low $(20 \mu \mathrm{g} / \mathrm{L}, \square)$ and high concentration $(200 \mu \mathrm{g} / \mathrm{L}, \Delta)$ of $\mathrm{Cd}$-exposed groups. The classes were presented as mean \pm standard deviation (as associated standard error) of PC scores for each group of clam samples.

anaerobically, together with the metabolite of succinate in invertebrate [34]. In this work, the high levels of both alanine and succinate demonstrated the enhanced anaerobiosis in clam induced by these two concentrations of $\mathrm{Cd}$.

As known organic osmolytes, homarine and betaine plays important roles in osmotic regulation in marine mollusks [32]. The increased homarine implied the ostomic stress caused by the low concentration $(20 \mu \mathrm{g} / \mathrm{L})$ of $\mathrm{Cd}$. However, the decreased betaine might be used to compensate the increase of amino acids and homarine involved in osmotic regulation in the low concentration $(20 \mu \mathrm{g} / \mathrm{L})$ of $\mathrm{Cd}$-treated clam group.

Two amino acids, tyrosine and phenylalanine, were increased in the high concentration $(200 \mu \mathrm{g} / \mathrm{L})$ of $\mathrm{Cd}$-treated clam group. However, both homarine and betaine were not significantly altered. Although both concentrations of $\mathrm{Cd}$ induced similar metabolic responses (BCAAs, alanine, arginine, etc.), these four differentially altered metabolic responses clearly implied the differential responsive mechanisms of osmotic stress induced by these two $\mathrm{Cd}$ exposures (20 and $200 \mu \mathrm{g} / \mathrm{L}$ ). Aspartate was uniquely depleted in the high concentration $(200 \mu \mathrm{g} / \mathrm{L})$ of Cd-treated clam group. Aspartate, an important intermediate in amino acids metabolism, is involved in multiple biological processes including biosynthesis of amino acids, urea cycle and gluconeogenesis. In another metabolic pathway, however, there was substantial conversion of aspartate to succinate under anoxic conditions in mollusk hence with decreased aspartate and increased succinate [35]. Interestingly, decreased aspartate and increased succinate were found in the high concentration $(200 \mu \mathrm{g} / \mathrm{L})$ of $\mathrm{Cd}$-treated clam group. Therefore, the increased alanine and succinate and decreased aspartate supported the occurrence of anaerobiosis metabolism induced by the high concentration $(200 \mu \mathrm{g} / \mathrm{L})$ of $\mathrm{Cd}$ in clam digestive glands, via two metabolic pathways, including aspartate conversion and glucose breakdown.

In summary, multiple biochemical indices were tested to characterize the biological effects induced by two concentrations (20 and $200 \mu \mathrm{g} / \mathrm{L}$ ) of $\mathrm{Cd}$ in the digestive glands of clam $R$. philippinarum. The values of total haemocyte count, reactive oxygen species and antioxidant enzymes exhibited that $\mathrm{Cd}$ induced dose-dependent immune and oxidative stresses in clam digestive glands. At metabolite level, results indicated that both Cd exposures caused immune stress marked by the elevated branched chain amino acids (valine, leucine and isoleucine). Although both low and high concentrations of $\mathrm{Cd}$ induced osmotic stress, the differential metabolic 

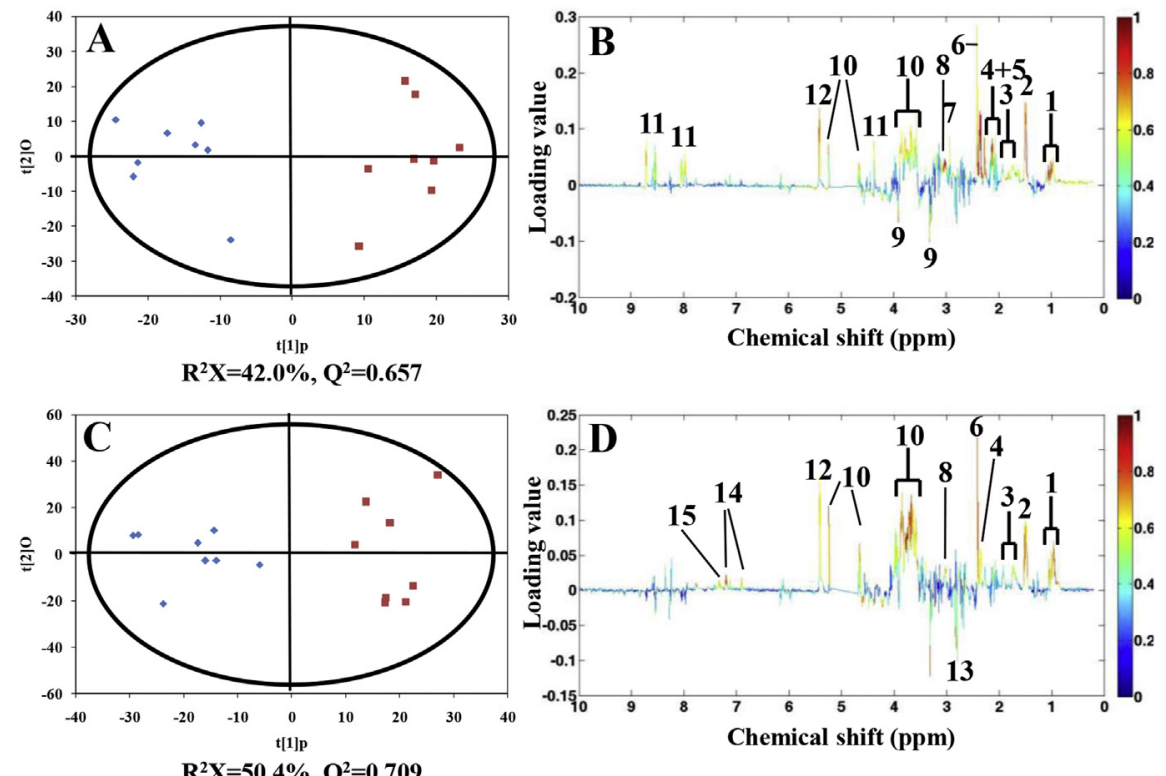

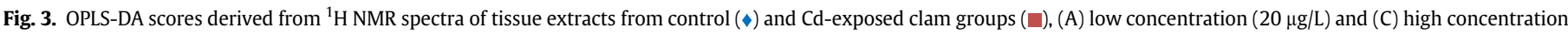

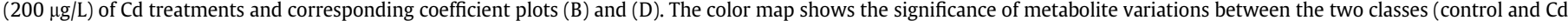

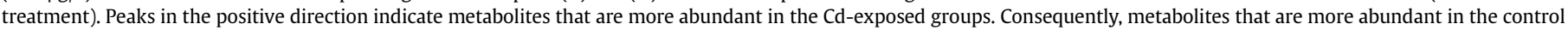

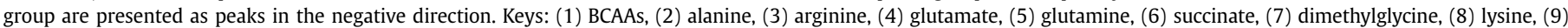

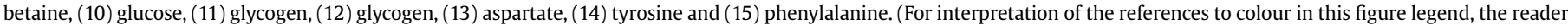
is referred to the web version of this article.)

biomarkers, such as homarine, betaine, tyrosine and phenylalanine, suggested the differential responsive mechanisms in clam digestive glands. In addition, both $\mathrm{Cd}$ treatments enhanced the anaerobiosis metabolism in clam digestive glands via differential metabolic pathways. This work demonstrated that multiple biomarkers characterized by a combined bottom-up and top-down approach could elucidate the biological effects of $\mathrm{Cd}$ in clams.

\section{Acknowledgments}

This work was supported by National Key Basic Research Program of China (2015CB453303) and Natural Science Foundation of Shandong Province (No. JQ201310). We thank Prof. Mark Viant (School of Bioscience, The University of Birmingham) for the use of ProMetab software.

\section{References}

[1] K. Broeg, H.V. Westernhagen, S. Zander, W. Körting, A. Koehler, The "bioeffect assessment index" (BAI): a concept for the quantification of effects of marine pollution by an integrated biomarker approach, Mar. Pollut. Bull. 50 (2005) 495-503.

[2] X. Zhang, Investigation of pollution of $\mathrm{Pb}, \mathrm{Cd}, \mathrm{Hg}$, as in sea water and deposit of Bohai Sea area, Heilongiiang Environ. J. 25 (2001) 87-90.

[3] G. Bertin, D. Averbeck, Cadmium: cellular effects, modifications of biomolecules, modulation of DNA repair and genotoxic consequences (a review), Biochimie 88 (2006) 1549-1559.

[4] R. Company, A. Serafim, M.J. Bebianno, R. Cosson, B. Shillito, A. Fiala-Médioni, Effect of cadmium, copper and mercury on antioxidant enzyme activities and lipid peroxidation on the gills of the hydrothermal vent mussel Bathymodiolus axoricus, Mar. Environ. Res. 58 (2004) 377-381.

[5] C. Li, H. Sun, A. Chen, X. Ning, H. Wu, S. Qin, Q. Xue, J. Zhao, Identification and characterization of an intracellular $\mathrm{Cu}, \mathrm{Zn}$-superoxide dismutase (icCu/ Zn-SOD) gene from clam Venerupis philippinarum, Fish Shellfish Immunol. 28 (2010) 499-503.

[6] L. Zhang, X. Liu, L. Chen, L. You, D. Pei, M. Cong, J. Zhao, C. Li, D. Liu, J. Yu, $\mathrm{H}$. Wu, Transcriptional regulation of selenium-dependent glutathione peroxidase from Venerupis philippinarum in response to pathogen and contaminants challenge, Fish Shellfish Immunol. 31 (2011) 831-837.

[7] L. Zhang, L. Qiu, H. Wu, X. Liu, L. You, D. Pei, L. Chen, Q. Wang, J. Zhao, Expression profiles of seven glutathione S-transferase (GST) genes from
Venerupis philippinarum exposed to heavy metals and benzo[a]pyrene, Comp. Biochem. Physiol. Part C 155 (2012) 517-527.

[8] J. Zhao, L. Qiu, X. Ning, A. Chen, H. Wu, C. Li, Cloning and characterization of an invertebrate type lysozyme from Venerupis philippinarum, Comp. Biochem. Physiol. Part B 156 (2010) 56-60.

[9] A. Elbaz, Y.Y. Wei, Q. Meng, O. Zheng, Z.M. Yang, Mercury-induced oxidative stress and impact on antioxidant enzymes in Chlamydomonas reinhardtii, Ecotoxicology 19 (2010) 1285-1293.

[10] T.D. Williams, N. Turan, A.M. Diab, H. Wu, C Mackenzie, K.L Bartie, O. Hrydziuszko, B.P. Lyons, G.D. Stentiford, J.M. Herbert, J.K. Abraham, I. Katsiadaki, M.J. Leaver, J.B. Taggart, S.G. George, M.R. Viant, K.J. Chipman, F. Falciani, Towards a system level understanding of non-model organisms sampled from the environment: a network biology approach, PLoS Comput. Biol. 7 (2011) 1-20.

[11] X. Liu, C. Ji, J. Zhao, Q. Wang, F. Li, H. Wu, Metabolic profiling of the tissuespecific responses in mussel Mytilus galloprovincialis towards Vibrio harveyi challenge, Fish Shellfish Immunol. 39 (2014) 372-377.

[12] C. Ji, H. Wu, L. Wei, J. Zhao, iTRAQ-based quantitative proteomic analyses on the gender-specific responses in mussel Mytilus galloprovincialis to tetrabromobisphenol A, Aquat. Toxicol. 157 (2014) 30-40.

[13] H. Wu, C. Ji, L. Wei, J. Zhao, Evaluation of protein extraction protocols for 2DE in marine ecotoxicoproteomics, Proteomics 13 (2013) 3205-3210.

[14] H. Wu, X. Zhang X. Li, Z Li, Y. Wu, F. Pei, Comparison of metabolic profiles from serum for the hepatotoxin-treated rats by NMR spectroscopic-based metabonomic analysis, Anal. Biochem. 340 (2005) 99-105.

[15] X. Zhang, H. Wu, P. Liao, X. Li, J. Ni, F. Pei, NMR-basedmetabonomic study on the subacute toxicity of aristolochic acid in rats, Food Chem. Toxicol. 44 (2006) 1006-1014.

[16] T.D. Williams, H. Wu, E. Santos, J. Ball, I. Katsiadaki, M.M. Brown, P. Baker F. Ortega, F. Falciani, J.A. Craft, C.R. Tyler, J.K. Chipman, M.R. Viant, Hepatic transcriptomic and metabolomic responses in the stickleback (Gasterosteus aculeatus) exposed to environmentally relevant concentrations of dibenzanthracene, Environ. Sci. Technol. 43 (2009) 6341-6348.

[17] H. Wu, W.-X. Wang, Tissue-specific toxicological effects of cadmium in green mussel (Perna viridis): nuclear magnetic resonance-based metabolomics study, Environ. Toxicol. Chem. 30 (2011) 806-812.

[18] E. Santos, J.S. Ball, T.D. Williams, H. Wu, F. Ortega, R. Van Aerle, I. Katsiadaki, F. Falciani, M.R. Viant, J.K. Chipman, C.R. Tyler, Identifying health impacts of exposure to copper using transcriptomics and metabolomics in a fish model Environ. Sci. Technol. 44 (2010) 820-826.

[19] L. Zhang, X. Liu, L. You, D. Zhou, Q. Wang, F. Li, M. Cong, L. Li, J. Zhao, D. Liu, J. Yu, H. Wu, Benzo(a)pyrene-induced metabolic responses in Manila clam Ruditapes philippinarum by proton nuclear magnetic resonance $\left({ }^{1} \mathrm{H}\right.$ NMR based metabolomics, Environ. Toxicol. Pharmacol. 32 (2011) 218-225.

[20] L. Zhang, X. Liu, L. You, D. Zhou, H. Wu, L. Li, J. Zhao, J. Feng, J. Yu, Metabolic responses in gills of Manila clam Ruditapes philippinarum exposed to copper using NMR-based metabolomics, Mar. Environ. Res. 72 (2011) 33-39. 
[21] M. Delaporte, P. Soudant, J. Moal, C. Lambert, C. Quéré, P. Miner, G. Choquet, C. Paillard, J. Samain, Effect of a mono-specific algal diet on immune functions in two bivalve species - Crassostrea gigas and Ruditapes philippinarum, J. Exp. Biol. 206 (2003) 3053-3064.

[22] J. Feng, J. Li, H. Wu, Z. Chen, Metabolic responses of HeLa cells to silica nanoparticles by NMR-based metabolomic analyses, Metabolomics 9 (2013) 874-886.

[23] X. Liu, L. Zhang, L. You, M. Cong, J. Zhao, H. Wu, C. Li, D. Liu, J. Yu, Toxicological responses to acute mercury exposure for three species of Manila clam Ruditapes philippinarum by NMR-based metabolomics, Environ. Toxicol. Pharmacol. 31 (2011) 323-332.

[24] M. Bradford, A rapid and sensitive method for the quantification of microgram quantities of protein utilizing the principle of protein-dye binding, Anal. Biochem. 72 (1976) 248-254.

[25] L. Li, X. Liu, L. You, L. Zhang, J. Zhao, H. Wu, Uptake pathways and subcellular fractionation of $\mathrm{Cd}$ in the polychaete Nereis diversicolor, Ecotoxicology 21 (2012) 104-110

[26] M.J. Bebianno, M.A. Serafim, Comparison of metallothionein induction in response to cadmium in the gills of the bivalve mollusks Mytilus galloprovincialis and Ruditapes decussates, Sci. Total. Environ. 214 (1998) 123-131.

[27] R.K. Pipe, J.A. Coles, Environmental contaminants influencing immune function in marine bivalve molluscs, Fish Shellfish Immunol. 5 (1995) $581-595$.
[28] H.I. Reid, P. Soudant, C. Lambert, C. Paillard, T.H. Birkbeck, Salinity effects on immune parameters of Ruditapes philippinarum challenged with Vibrio tapetis, Dis. Aquat. Org. 56 (2003) 249-258.

[29] C. Yang, S. Liu, S. Zhou, H. Wu, J. Yu, C. Xia, Allelochemical ethyl 2-methyl acetoacetate (EMA) induces oxidative damage and antioxidant responses in Phaeodactylum tricornutum, Pestic. Biochem. Physiol. 100 (2011) 93-103.

[30] Z. Li, H. Wu, X. Zhang, X. Li, P. Liao, W. Li, F. Pei, Investigation on the acute biochemical effects of light rare earths (lanthanum and cerium) by NMRbased metabonomic approaches, Chem. J. Chin. Univ. 27 (2006) 438.

[31] X. Liu, C. Yang, L. Zhang, L. Li, S. Liu, J. Yu, L. You, D. Zhou, C. Xia, J. Zhao, H. Wu, Metabolic profiling of cadmium-induced effects in one pioneer intertidal halophyte Suaeda salsa by NMR-based metabolomics, Ecotoxicology 20 (2011) $1422-1432$.

[32] M.R. Viant, E.S. Rosenblum, R.S. Tjeerdema, NMR-based metabolomics: a powerful approach for characterizing the effects of environmental stressors on organism health, Environ. Sci. Technol. 37 (2003) 4982-4989.

[33] P.C. Calder, Branched chain amino acids and immunity, J. Nutr. 136 (2006) 288S-293S.

[34] T.M. Stokes, A. Awapara, Alanine and succinate as end-products of glucose degradation in the clam Rangia cuneata, Comp. Biochem. Physiol. 25 (1968) $883-892$.

[35] R.A. Graham, W.R. Ellington, Anaerobic aspartate metabolism and the formation of alanine in molluscan cardiac muscle: a ${ }^{13} \mathrm{C}$ NMR study, J. Exp. Zool. 236 (1985) 365-370. 